\title{
TCR Signaling in T Cell Memory
}

\author{
Mark A. Daniels and Emma Teixeiro* \\ Department of Molecular Microbiology and Immunology, School of Medicine, University of Missouri, Columbia, MO, USA
}

$\mathrm{T}$ cell memory plays a critical role in our protection against pathogens and tumors. The antigen and its interaction with the $T$ cell receptor (TCR) is one of the initiating elements that shape $T$ cell memory together with inflammation and costimulation. Over the last decade, several transcription factors and signaling pathways that support memory programing have been identified. However, how TCR signals regulate them is still poorly understood. Recent studies have shown that the biochemical rules that govern $\mathrm{T}$ cell memory, strikingly, change depending on the TCR signal strength. Furthermore, TCR signal strength regulates the input of cytokine signaling, including pro-inflammatory cytokines. These highlight how tailoring antigenic signals can improve immune therapeutics. In this review, we focus on how TCR signaling regulates T cell memory and how the quantity and quality of TCR-peptide-MHC interactions impact the multiple fates a T cell can adopt in the memory pool.

Keywords: $\mathrm{T}$ cell receptor, $\mathrm{T}$ cell, protective immunity, immune memory, signaling

\section{OPEN ACCESS}

Edited by:

Dietmar Zehn,

Swiss Vaccine Research Institute,

Switzerland

Reviewed by:

Jose Alberola-lla,

Oklahoma Medical Research

Foundation, USA

Cosima T. Baldari,

University of Siena, Italy

*Correspondence:

Emma Teixeiro

teixeiropernase@missouri.edu

Specialty section:

This article was submitted to T Cell

Biology, a section of the

journal Frontiers in Immunology

Received: 15 September 2015

Accepted: 25 November 2015

Published: 10 December 2015

Citation:

Danie/s MA and Teixeiro E (2015) TCR

Signaling in T Cell Memory.

Front. Immunol. 6:617.

doi: 10.3389/fimmu.2015.00617

\section{INTRODUCTION}

Upon infection or vaccination, $\mathrm{T}$ cell receptors (TCRs) recognize antigen bound to MHC molecules on the surface of antigen-presenting cells (APCs). Antigen recognition results in the transduction of TCR signals that enable T cell differentiation. In this process, TCR signals cooperate with cytokine, costimulatory, chemokine, integrin, and metabolic signals to regulate the acquisition of effector function and the generation of T cells with very different phenotypes. The degree of synergy between all the signals mentioned above leads to changes in the levels of a set of transcription factors that ultimately will determine distinct $\mathrm{T}$ cell fates. These include $\mathrm{CD} 8$ short-lived effectors, $\mathrm{CD} 4 \mathrm{~T}$ helper: Th1, Th2, follicular helper T cell (Tfh), GC (germinal center)-Tfh, T cell effector-memory cells $\left(\mathrm{T}_{\mathrm{EM}}\right), \mathrm{T}$ cell central-memory cells $\left(\mathrm{T}_{\mathrm{CM}}\right), \mathrm{T}$ cell resident memory cells $\left(\mathrm{T}_{\mathrm{RM}}\right), \mathrm{T}$ memory stem cell, or lymphopenia-induced proliferation (LIP)-memory T cell, etc.

Although a great body of work supports the contribution of the inflammatory and local tissue environments to $\mathrm{T}$ cell differentiation and memory, emerging data suggest that TCR signaling itself is crucial in this process, especially for $\mathrm{T}$ cell memory development. In this review, we discuss these data and propose the idea that TCR signaling is an essential component that enables the integration of environmental cues that shape the T cell memory pool.

\section{TCR SIGNAL QUANTITY, QUALITY, AND T CELL FATE}

$\mathrm{T}$ cell receptor signals are conditioned by different biophysical and biochemical parameters. The affinity of the TCR $\alpha \beta$ heterorodimer for antigenic peptide-MHC molecules (pMHC), the dose of antigen presented on the surface of APCs, and the duration of the TCR-pMHC interaction, all determine the strength of TCR signals $(1,2)$. For a long time, the prevalent idea has been that memory development requires an intermediate to high overall signal strength. Signals that were too weak resulted in only a few memory cells that were not fit to survive or respond. By contrast, signals 
that were too strong led to terminally differentiated effectors (3). This idea holds true on studies focused on $\mathrm{T}$ cell clones that respond to immunodominant epitopes or that bind with high affinity to cognate antigens. In these studies, these high-affinity $\mathrm{T}$ cells are recruited in large frequencies to the memory pool, in part due to their greater expansion (4-8). However, in the context of infection or lymphopenia, even very low affinity antigens support memory development (9-13). These data suggest that TCR affinity alone is not predictive of memory outcome. Indeed, other studies have found the duration or $t 1 / 2$ of the PMHC-TCR interaction (both equilibrium and aggregate half-life) can serve as a better predictor of memory fate $(14,15)$. Thus, recent work has shown that Th1 memory fate correlates with long TCR-pMHC $t 1 / 2$ times and not with the affinity of the pMHC-TCR interaction or the ability to expand (16). The relationship between TCR-pMHC I dwell time and CD8 T cell memory commitment is currently less clear. It is most likely distinct from CD4 T cells, especially when considering the different contributions of CD4 and CD8 co-receptors to the stability of the TCR-pMHC interaction and the narrower range of effector functions for CD8 T cells $(17,18)$. The timing and availability of the antigen is also important for making the memory "choice." One report has suggested that earlysustained T cell-APC interactions were absolutely required for the response of memory cells (but dispensable for the acquisition of effector function), although a clear effect in memory generation was not provided (19). By contrast, other reports have shown that shortening TCR stimulation early or late in the response favors the generation of memory T cells (20-23). Collectively, these studies illustrate that a strict quantitative model of TCR signaling cannot easily explain $\mathrm{T}$ cell memory commitment/function and suggest that the efficiency of an antigen to assemble the TCR signals that specifically support memory may be more complex than originally anticipated.

An alternative to the quantitative model of TCR signaling for memory is a model that considers the quality of TCR signaling. In other words, the TCR signals that support the development of memory may be qualitatively different from the ones required for other $\mathrm{T}$ cell functions (effector function or proliferation). TCR signal quality could be determined by the strength of the TCR signal. In this line, Jenkins and colleagues recently showed how differences in antigen dose/aggregate p-MHCII dwell time can lead to different CD4 T cell lineage choices. They posit a model where a low amount of TCR signaling supports Tfh development, an intermediate amount induces Th1, and large amounts of TCR signaling enables GC-Tfh differentiation $(15,24)$. For CD8 T cells, a decreasing potential model has been proposed where the weaker the signal a T cell receives (over a certain threshold), the higher the likelihood of the cell to enter in the memory pool $(25,26)$. This model does not distinguish between antigenic or inflammatory signals nor does it take into account the input of signals from the local tissue environment in determining the phenotypic diversity of the memory pool. However, it is consistent with the fact that very weak TCR signals (even in the range of self) are sufficient to support the memory program $(10,12)$.

In light of this, it is possible that different $\mathrm{T}$ cell outcomes are achieved at different TCR signaling thresholds. This is not a novel concept [reviewed in Ref. $(27,28)]$. Seminal work by Valittutti and Lanzavechia originally determined that proliferation required higher antigen doses than IFN $\gamma$ secretion or cytotoxicity in human $\mathrm{T}$ cell clones (29). In vivo, it has also been reported that CD8 T cell proliferation requires longer and higher affinity TCR-pMHC interactions than what is required for the acquisition of effector function or memory differentiation $(10,30)$. Thus, memory fate may be supported by low-grade TCR signals, which are sufficient for the acquisition of memory programing but are not strong or continuous enough to "burn the differentiating T cell to death." Consistent with this, $\mathrm{T}$ cells favor the expression of memoryassociated transcription factors (23) and preferentially develop into protective memory $\mathrm{T}$ cells in the context of very weak TCR signals $(10,13,23)$. These, together with the fact that memory precursors can be detected early in the immune response raises the hypothesis that memory development may be a default pathway whose TCR signaling threshold is lower than the threshold required for full expansion or to become short-lived effector (26, $31)$. T cells survival capacity may be established depending on the signals that the individual $\mathrm{T}$ cell clones continue to experience during the course of an immune response. That is, $\mathrm{T}$ cells exposed to strong or continued signals become short-lived effectors destined to die (32), whereas T cells receiving slightly weaker signals are directed into the $\mathrm{T}_{\mathrm{EM}}$ phenotype. This fosters the intriguing idea that very early in the response a set of $\mathrm{T}$ cells are directed down the memory path, perhaps, to ensure diversity within the memory pool $(33,34)$.

Given that $\mathrm{T}$ cells can give rise to a battery of daughter cells of very different phenotypes and fates; most likely, T cells are not predetermined to acquire a specific outcome at the naïve level (35-37). Therefore, qualitatively different biochemical input must determine each of the fates a $\mathrm{T}$ cell can adopt during an immune response. These qualitatively different biochemical signals may be defined early in the response or progressively, by a combination of factors that act at the same time, or in a multistage process. It is clear that inflammation and tissue-specific signals shape the phenotypic determination of $\mathrm{T}$ effector and memory cells; yet, experimental evidence still indicates that TCR signals, by themselves, are key at inducing memory programs and enabling the $\mathrm{T}$ cells ability to receive the extrinsic signals that help to determine the diversity of $\mathrm{T}$ cell fates $(1,23,24,38)$. In this scenario, TCR signal quality may be defined independently of the quantity of the TCR signal and dictated by the singular ability of the antigen to efficiently assemble a "signalosome" for memory fate that is distinct from the one required for other $T$ cell functions (discussed in detail below). This is supported by studies where a point mutation in one of the constant domains of the TCR allows for expansion and acquisition of effector function but severely impairs CD8 memory development (39). In this model, the properties of the TCR-pMHC interactions are intact, affinity and dwell time are not compromised. Furthermore, there is not an overall reduction in TCR signaling but rather a defect only in the activation of TCR-dependent NFKB signaling (39). Thus, TCR signaling to memory may be defined by the ability of the antigen to induce the activation of specific signaling pathways key to launch the memory program. In agreement with this, specific inhibition of other signaling pathways, such as Wnt, mTOR, or NFKB, affects T cell memory fate decisions very differently (39-41). 


\section{TCR SIGNAL STRENGTH IMPACTS TCR SIGNAL QUALITY}

At the risk of being confusing, it is still important to note that the composition of the "memory TCR signalosome" may also change depending on the TCR signal strength. Thus, while the transcriptional signatures that describe the different "flavors" of memory cells may be unique, there may be multiple intracellular signaling options that lead to each fate. Evidence for this has been revealed in studies where T cells defective in the TCR signalosome that supports memory in the context of strong TCR signaling, strikingly were able to regain the ability to differentiate into memory upon challenge with weak antigens (42). In this case, memory development correlated with the capacity to activate NFKB signals and happened even when the activation of other signaling pathways was impaired (42). This suggests that weak and strong TCR ligands induce distinct signalosomes rather than different levels of the same signalosome. Similar conclusions can be reached from the studies of Tubo and Jenkins where depending on the TCR signal strength/TCR-pMHC dwell time/antigen dose, distinct transcriptional profiles could be achieved that supported Tfh, Th1, and GC-Tfh $(15,24)$. Whether the transcriptional profiles that lead to distinct lineages are governed by the early induction of different TCR signalosomes or controlled by different negative feedback circuits at the level of the nuclei or both remains to be determined.

How can different TCR signal strengths imprint distinct biochemical signatures that lead to different $\mathrm{T}$ cell fates? A model for CD4 T helper differentiation has been proposed where the TCR can support two types of signals (24). One is induced by default and commits the cells into a lineage. This may be the case of the signal that supports Bcl-6 expression in Tfh. The other signal is proportional to the strength of the TCR and implies the expression of other transcription factors, such as Blimp-1 and T-bet for Th1 $(43,44)$. The higher the dose of antigen, the higher the proliferation and the generation of the progeny of the originally committed Th1 clones. When the TCR signal is too strong, however, Blimp-1 levels are induced to high levels leading to apoptosis of Th1 clones $(45,46)$. On the other hand, the Tfh clones that originally committed to this lineage, proliferate, induce higher levels of Bcl-6, and eventually differentiate into GC-Tfh (24). A similar model could be applied to CD8 T cells, where a default signal triggered by any engaged TCR, even in the context of very weak TCR ligands, could induce the expression of memoryassociated factors Bcl-6 and Eomes (but low levels of Blimp-1 and T-bet) (23). In these conditions, weak TCR ligands would favor the generation of memory $\mathrm{T}$ cells with a $\mathrm{T}_{\mathrm{CM}}$ phenotype over the generation of effector CD8 cells. If $\mathrm{T}$ cells encounter stronger TCR signals, then the ratio of Bcl-6/Eomes to Blimp-1/Tbet transcription factors would change. Now, T-bet and Blimp-1 expression would increase, supporting the generation of a large number of effector cells. When the antigenic signal is too strong, T-bet and Blimp-1 levels would increase and Bcl-6 and Eomes levels decrease. This would force the $\mathrm{T}$ cells that took the effector path to continue dividing and die $(23,44)$. By contrast, $\mathrm{T}$ cells that received an intermediate TCR signal would be skewed into memory due to a decrease in their T-bet/Blimp-1 levels and/or a natural recovery of the default signal that keeps high levels of Eomes and Bcl-6. Therefore, the TCR signal strength a T cell or their progeny receives may dictate its longevity while specific phenotypes may be further shaped by a continuum of antigenic signals, inflammatory cytokines, and local environmental factors encountered in the course of the response. In agreement with this, very low affinity TCR ligands induce a signal that supports high Eomes/T-bet ratios and high levels of Bcl6 that favor memory development. By contrast, high-affinity TCR ligands at the same dose support low Eomes/T-bet ratios (23) (Figure 1).

This model reconciles the idea of "one cell-multiple fates" with the current models of memory ontogeny. However, it is difficult to test in $\mathrm{T}$ cell population studies that cannot track the antigenic experience of individual cells or distinguish between the different precursors of each $\mathrm{T}$ cell fate. One question, though, remains to be explained in this model. This is what keeps a $\mathrm{T}$ cell in the naïve stage versus the $\mathrm{T}$ cell that develops into memory $\left(\mathrm{T}_{\mathrm{CM}}\right)$ under very weak TCR signaling. The answer to this question may lie in the dose of the weak antigen and the cytokine milieu. For example, $\mathrm{T}$ cells exposed to high doses of weak antigens (in lymphopenic conditions) and cytokines IL-7 and IL-15 differentiate into cells of a $\mathrm{T}_{\mathrm{CM}}$ memory phenotype (13). Alternatively, the ability of a $\mathrm{T}$ cell to remain naïve or differentiate into a $\mathrm{T}_{\mathrm{CM}}$ phenotype may depend on the TCR signals that it received during thymic development. A hint of how this process may be modulated comes from studies monitoring $\mathrm{CD} 5^{\mathrm{hi}}$ and $\mathrm{CD} 5^{\text {lo }} \mathrm{T}$ cell populations in the periphery. Expression of CD5, a negative regulator of TCR signals $(47,48)$, directly correlates with the strength of the signal generated by the selecting self-pMHC ligand encountered in the thymus. Despite this, peripheral $\mathrm{CD} 5^{\mathrm{hi}} \mathrm{T}$ cells exhibit a pre-activated profile that after TCR stimulation leads to stronger responses (49-51). It is possible that the expression of CD5 conditions whether a naïve $\mathrm{T}$ cell responding to foreign antigen will reach a TCR signaling threshold that will direct it into one $\mathrm{T}$ cell fate or another. Although this has not been formally tested, these studies point to the idea that a T cell's TCR signal history can greatly influence its fate as the environment around it changes (inflammation, tissue distribution, etc.).

\section{HOW TCR SIGNALING REGULATES MEMORY DEVELOPMENT}

In recent years, the field has focused a great deal of attention on inflammation and other extrinsic factors and has relegated TCR/antigenic signals to have a minimal role in the process that establishes the clonal heterogeneity of the T cell effector or memory pool. Recent work has brought the TCR back to the forefront of this debate. We have generated a mouse model where $\mathrm{T}$ cells bearing a point mutation in the transmembrane domain of the TCR $\beta$ chain ( $\beta$ TMDmut) exhibit partial TCR signaling but no other alterations in peptide-MHC-TCR recognition or cytokine signaling. Upon Listeria infection, $\beta$ TMDmut cells were severely defective in generating memory $\mathrm{T}$ cells and memory responses (39). This was despite the normal ability of the $\beta$ TMDmut cells to proliferate and differentiate into effector $\mathrm{T}$ cells. Interestingly, the defect in TCR signaling to memory led to a failure to generate "IL-7R hi -memory precursors," and it was not due to impairment 


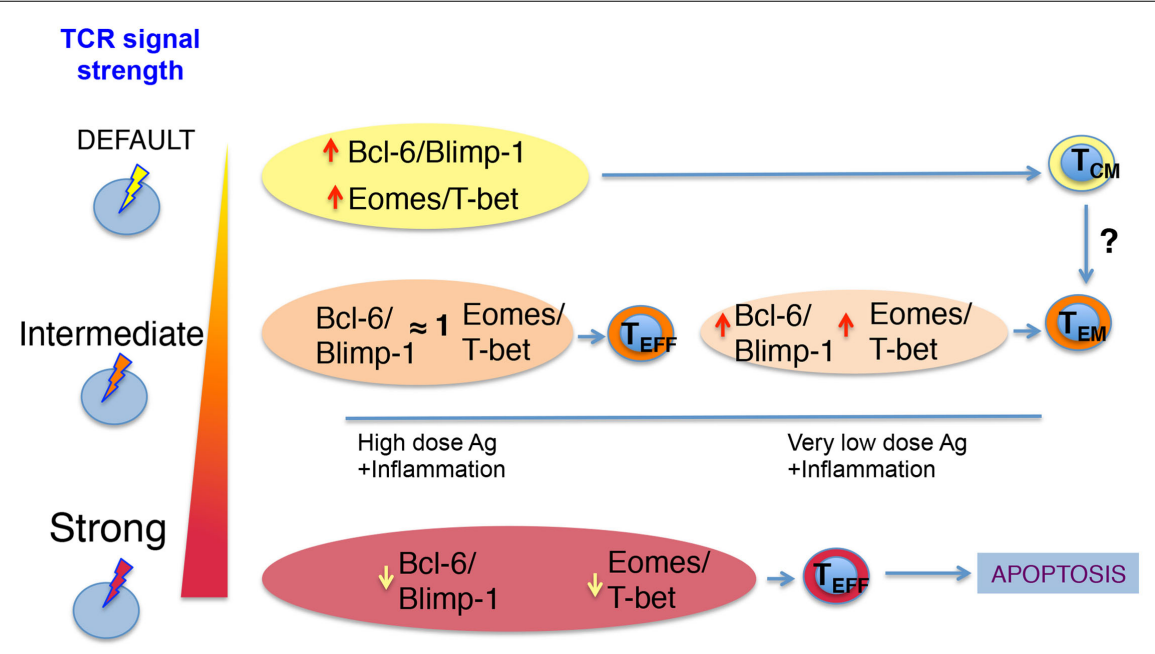

FIGURE 1 | Proposed model of how TCR signal strength regulates CD8 T cell memory differentiation. The interactions of TCR-pMHC on a naïve CD8 T cell triggers TCR signals of varying strength. A default TCR signal leads to low levels of T-bet and Blimp-1 and higher levels of Eomes and Bcl- 6 skew the naïve T cell into a central-memory phenotype. This weak TCR signal can be achieved by strong or very weak ligands. If the TCR signal is intermediate, then T cells integrate IL-2 and other pro-inflammatory signals, which allow for similar up-regulation of all transcription factors depicted. This ensures the acquisition of effector function early in the response. Once antigen and inflammation decrease due to clearance of the pathogen, effector T cells decrease their levels of Blimp-1 and T-bet and regain higher ratios of Bcl-6/Blimp-1 and Eomes/T-bet allowing them to become memory T cells. For the cases where the naïve T cell receives very strong TCR signals, the Bcl-6/Blimp-1 and Eomes/T-bet ratios are too low and ultimately lead to apoptosis.

in receiving inflammatory or homeostatic input (42). These results challenged the idea that the TCR is a mere spark plug in the T cell memory differentiation process and showed that the TCR signaling requirements are not the same for all $\mathrm{T}$ cell outcomes. This idea is further supported by a study from Smith-Garvin and colleagues, which also explored the role of TCR signaling in CD8 T cell differentiation by targeting a downstream intermediate of the TCR signalosome, SLP-76. Employing a knock-in mouse model that express mutant SLP-76, they showed compelling evidence that the TCR signaling requirements for CD8 effector and memory development are different (52). Furthermore, another study using a conditional SLP-76 model also suggested that tonic TCR signals are required beyond the peak of the response to maintain memory CD4 T cell homeostasis and to regulate CD8 memory generation $(53,54)$. Noteworthy, these and other recent studies $(52,55,56)$ have also helped to consolidate the idea that not all the fates that a $\mathrm{T}$ cell can adopt are interrelated; that the potential of a $\mathrm{T}$ cell to choose the path toward a specific fate and not another can already be determined early in the response; and finally, that not only extrinsic factors but also cell intrinsic TCR-dependent signals or programs may be important to establish the heterogeneity of the effector and memory pools.

How TCR signaling to memory is defined biochemically at the level of signal transduction, transcriptional regulation, and metabolism is beginning to come to light. TCR stimulation results in the activation of several signaling pathways [such as $\mathrm{Ca}^{2+/} \mathrm{NFAT}$; CBM/PKC $/ \mathrm{NF} \kappa \mathrm{B}$, Vav/Rac/POSH/JNK, RasGRP, or Sos-Ras/RafK/ERK, PI3K, mTOR, Wnt $(57,58)]$ that, in some cases, are shared with other surface receptors. This is the case for CD28, chemokine receptors, or some TNF receptors that can each utilize membrane proximal intermediates of TCR signaling, such as PI3K or PKCO (59-61). To date, attempts to demonstrate the role of these specific pathways in $\mathrm{T}$ cell differentiation have implied the use of gain/loss of function approaches based on the overexpression of dead or constitutive active forms or a complete deletion of intermediates of the signaling cascades under study. It is important to keep in mind that these approaches can lead to an imbalance in the signaling cross-talk that naturally occurs in a $\mathrm{T}$ cell under physiological conditions. Thus, while the conclusions of these studies are extremely informative regarding the role of the specific signaling intermediates in T cell differentiation, they cannot be exclusively ascribed to the TCR. We generated a TCR transgenic model where T cells bearing TCRs mutant in the $\beta$ TMD are specifically deficient in memory differentiation. This model allowed us to connect TCR with signal transduction to memory. We found that the memory defect was not a consequence of an overall change in the activation of the signaling pathways supported by the TCR signalosome. By contrast, memory differentiation-defective $\mathrm{T}$ cells were singularly impaired in the induction of the NFKB signaling pathway (39). Furthermore, once $\beta$ TMDmut $T$ cells regained the ability to induce NFKB signals, their capacity to differentiate into memory $\mathrm{T}$ cells was restored (23). Together, these strongly suggest that TCR-dependent NFKB signaling is crucial for the generation of memory $\mathrm{T}$ cells.

$\mathrm{T}$ cell receptor-dependent $\mathrm{NF \kappa B}$ signaling involves the activation of PKC $\theta$, which enables the assembly of the Carma1/Bcl10/Malt1 (CBM) complex. The CBM complex, in turn, recruits the IKK complex (IKK $\alpha$, IKK $\beta$, and NEMO) to the membrane to be activated in a TRAF2/6 and TAK1dependent manner (62). The importance of NFKB signaling in memory development is manifested in EDA-ID (anhidrotic ectodermal dysplasia with immunodeficiency) patients, which

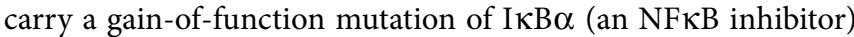
that leads to impaired $\mathrm{NF \kappa B}$ activation and a lack of memory 
T cells (63). Previous reports utilizing murine models targeting IKK $\beta$ or $I \kappa B \alpha$ in $T$ cells also indicated that NFKB signaling pathway was important for generation of memory-phenotype $\mathrm{T}$ cells $(64,65)$. More recently, other studies have also involved members of the non-canonical $\mathrm{NF} \kappa \mathrm{B}$ cascade in the development of memory $\mathrm{T}$ cells $(66,67)$. However, none of these studies revealed the biochemical mechanism behind the role of $\mathrm{NF} \kappa \mathrm{B}$ in $\mathrm{T}$ cell memory, and only the study by Parker and colleagues addressed its role in the context of infection (67).

An important aspect to consider regarding the NFKB pathway is its ability to regulate different $\mathrm{T}$ cell outcomes depending on the level of activation, the kinetics of activation, and the developmental stage or type of $\mathrm{T}$ cell. For example, deletion of IKK $\beta$ results in a defect in generating memory-phenotype T cells. By contrast, chronic activation of NFKB signaling in T cells responding to Listeria infection results in increased apoptosis, which results in defective memory (68). This may be related to the fact that IKK $\beta$, while essential for the induction of $\mathrm{NF \kappa B}$, is also involved in the negative regulation of the cascade and can inhibit early TCR signaling $(68,69)$. In addition, NFKB signals exhibit different waves of induction after stimuli have gone. How this contributes to $\mathrm{T}$ cell fate decisions is also not known (70-73). Finally, it is worthy to note that members of the TCR-dependent NFKB signaling cascade differ in their individual contributions to the final T cell outcome in CD8 versus CD4 T cells. Thus, constitutive activation of IKK $\beta$ leads to enhanced CD4 negative selection but has no effect on CD8 T cells (74). T-cell-specific deletion of NEMO or TAK1 prevents the development of both CD4 and CD8 peripheral $\mathrm{T}$ cells $(65,75)$. However, PKC $\theta$, Carma-1, or Bcl10 deletion do not appear to contribute to selection in the thymus, but are remarkably involved in CD4 regulatory $\mathrm{T}$ cell development. They also regulate Th17 and Th2, but not Th1 differentiation and contribute to the generation of CD4 memoryphenotype T cells $(60,76-78)$. Murine and human T cells lacking Carma-1 or Bcl-10 are inefficient at developing a CD8 and CD4 memory-phenotype $\mathrm{T}$ cells $(79,80)$, although the role of these intermediates in $\mathrm{T}$ cell memory development has not been fully characterized in the context of infection. An important role for TRAF-6 in CD8 T cell memory but not effector development has also been described (55). TRAF- 6 contributes to IKK $\gamma$ activation and NFKB induction and we have noticed that CD4 TRAF-6 deficient $\mathrm{T}$ cells exhibit defects in $\mathrm{I} \kappa \mathrm{B} \alpha$ phosphorylation and degradation, together with the described enhanced phosphorylation of PI3K/Akt (81). Interestingly, the role of TRAF-6 in CD8 $\mathrm{T}$ cell memory development is mediated by the regulation of fatty acid metabolism, although whether this occurs in an NFKBindependent fashion is unclear (55). Collectively, these studies show that NFKB-dependent $\mathrm{T}$ cell outcomes are determined by multiple and complex mechanisms. Thus, future research will need to consider all of the aspects described above to thoroughly understand how this signaling pathway regulates $\mathrm{T}$ cell effector responses and memory development.

Ras/ERK, PI3K/Akt, and mTOR signaling pathways are also induced upon TCR stimulation and have recently been linked to the development of memory T cells. Ras is a GTPase that is activated by Sos or RasGRP, both GEFs are actively regulated by the TCR signalosome (57). The isoform N-Ras is crucial for
ERK-independent regulation of CD8 T cell memory development via regulation of Eomes $(82,83)$. On the other hand, mTOR signaling was originally described as a key regulator of proinflammatory IL-12 and homeostatic IL-7 cytokine signals in CD8 memory programing, particularly through its control of the transcription factors T-bet and Eomes $(41,84)$. Additionally, mTOR is a central regulator of cell metabolism, growth, survival, and proliferation. mTORC1 (the rapamycin target) is activated upon TCR stimulation (85) via Carma-1 and Malt-1 (86); however, its continuous activation depends on the integration of TCR signals with other cytokine signals, such as IL-12 (41). mTORC2 plays a more important role in cell survival and cytoskeletal regulation (87) and can activate Akt to control mTORC1 (88). The relative contribution of mTORC1 and mTORC2 in T cell memory development has remained elusive, although a recent study by Powell and colleagues supports a differential role for these complexes in CD8 T cell effector/memory responses and memory maintenance (89). How the two mTOR complexes interpret differences in TCR signal strength in the context of other environmental cues to direct the metabolic changes that accompany the transition to memory is unclear. Remarkably, agonistic TCR stimulation results in strong activation of ERK and PI3K/Akt, both involved in the activation of high levels of mTORC1. This supports the idea that strong TCR signals are optimal for effector differentiation and may be detrimental for programing memory longevity via transcription factors such as IRF-4, Blimp-1, or T-bet that can suppress Eomes expression $(90,91)$. Little is known of how $\mathrm{T}$ cells switch from mTORC1- to mTORC2-dependent metabolism to transition from effector to memory. Similarly, it is unclear whether TCR signals regulate $\mathrm{mTORC} 2$ and their ability to control the metabolic reprograming that $\mathrm{T}$ cells need to differentiate into memory (89). When considering the TCR signal strength constraints of each of the Th subsets (1) with the fact that Th1 and Th17 differentiation is mTORC1 dependent while Th2 is mTORC2 dependent, it is tempting to speculate that $\mathrm{mTORC} 2$ might play a major role on memory $\mathrm{T}$ cells that have been selected on the basis of low TCR signals, such as $\mathrm{T}_{\mathrm{CM}}$ (89) or $\mathrm{T}_{\mathrm{RM}}$, which are highly dependent on Foxo $1 \rightarrow \mathrm{KLF} 2 \rightarrow \mathrm{S} 1 \mathrm{P} 1$ [a target of $\operatorname{mTORC} 2(92,93)]$. On the contrary, $\mathrm{T}_{\mathrm{EM}}$ cells that are selected in higher TCR signaling conditions might be more dependent on mTORC1.

Another signaling pathway important for memory generation is Wnt signaling. Inhibition of GSK3 $\beta$ mimics Wnt signaling and skews differentiating $\mathrm{T}$ cells into a memory stem cell phenotype that provides superior proliferative and antitumor capabilities (40, 94). Wnt signaling requirement for the generation of memory does not appear to require $\beta$-catenin (95) but rather targets the transcription factor TCF-1 to regulate Eomes expression (96). TCR signaling can activate Wnt signaling via PI3K/Akt and PKC $(40,97)$. However, constitutive active Akt signaling diminishes TCF-1, Lef1, and Myc leading to a loss of memory T cells (98). This suggests that, similar to the NFKB pathway, PI3K/Akt signaling appear to have opposing effects on the survival or development of $\mathrm{T}$ cell memory depending on the level of activation. This, then, posits the idea that for at least some signaling pathways, there may be specific thresholds that a $\mathrm{T}$ cell needs to meet in order to progress into one $\mathrm{T}$ cell fate or another. Whether there is a set time in $\mathrm{T}$ cell differentiation where the level of the signaling pathway in 
question fully commits a T cell into a particular fate is not known. It is also possible that at any time intrinsic and extrinsic factors could both contribute to the total level of the specific signaling pathway and determine whether the $\mathrm{T}$ cell would progress toward a specific phenotype or another.

Finally, another complex and important issue is signaling crosstalk. Signaling pathways can often synergize and/or regulate each other. This applies to TCR signaling pathways and metabolic signaling pathways. For example, it is well known that NFKB signaling and GSK3 $\beta$ can modulate mTOR signaling $(99,100)$, and vice versa, mTOR signaling can also modify NFKB signaling (101). Therefore, special attention should be made to the interactions between signaling pathways and how they change depending on the environmental cues, especially when considering therapeutical approaches that aim to activate or suppress a specific signaling pathway.

\section{HOW TCR SIGNALING SHAPES THE PHENOTYPIC DIVERSITY OF MEMORY}

The memory pool is not homogenous and it is now well accepted that different $\mathrm{T}$ cell memory subsets, such as $\mathrm{T}_{\mathrm{SCM}}, \mathrm{T}_{\mathrm{CM}}, \mathrm{T}_{\mathrm{EM}}$, and $\mathrm{T}_{\mathrm{RM}}$ coexist. Each contributes in unique ways to provide full protection against re-infection. Recent studies are shedding light into how TCR signaling may be regulating each one of these memory fates. TCR-dependent NFKB signals are more important for CD8 $\mathrm{T}_{\mathrm{CM}}$ cells (23). Wnt signaling, however, appear to be crucial for CD8 $\mathrm{T}_{\mathrm{SCM}}$ (40) while sustained mTOR signaling is required for the accumulation of $\mathrm{T}_{\mathrm{RM}}$ in the mucosa (102).

The requirement of TCR signals for $\mathrm{T}_{\mathrm{RM}}$ is more controversial. Certain features of $\mathrm{T}_{\mathrm{RM}}$ such as $\alpha \mathrm{E} \beta 7$ expression may be upregulated in mucosal tissue independent of the presence of antigen. Indeed, cognate antigenic signals are not required for the development of $\mathrm{T}_{\mathrm{RM}}$ in the intestine, in the female reproductive tract, and in the skin $(103,104)$. On the other hand, $T_{R M}$ development in lung, CNS, and PNS requires antigen (105). Remarkably, none of these studies has assessed whether tonic self-peptide TCR signaling is required for $\mathrm{T}_{\mathrm{RM}}$ development or maintenance. Similarly, a fine distinction needs to be made regarding whether there is a TCR signal that favors the generation of $\mathrm{T}_{\mathrm{RM}}$ upon priming or whether this occurs within the tissue (106).

The relationship between TCR signaling transduction and CD4 $\mathrm{T}$ cell memory diversity is also not completely clear. Mounting evidence supports that TCR signal strength plays a role in the generation of $\mathrm{T}_{\mathrm{EM}}$ versus $\mathrm{T}_{\mathrm{CM}} \mathrm{CD} 4$ cells similar to $\mathrm{CD} 8 \mathrm{~T}$ cells, with strong TCR signals guiding the commitment to one of the $\mathrm{T}_{\mathrm{EM}}$ lineages and weaker stimulation favoring the generation of $\mathrm{T}_{\mathrm{CM}}$ (107). Recently, $\mathrm{T}_{\mathrm{EM}}$ (Th1-like) and $\mathrm{T}_{\mathrm{CM}}$ cell fates have been identified by virtue of their unique expression of T-bet or Bcl-6 (108). It is possible that strong TCR signals driving Th1 differentiation lead to high levels of Blimp-1, which consequently, would repress the expression of $\mathrm{Bcl}-6$, and commit Th1 effectors to the $\mathrm{T}_{\mathrm{EM}}$ fate (109). Weak TCR signals, in turn, could lead to low levels of Blimp-1 and T-bet and higher expression of Bcl6, supporting $\mathrm{T}_{\mathrm{CM}}$ differentiation. Alternatively, Bcl- 6 could be already expressed as a default and only $\mathrm{T}$ cells able to express high levels of IL-2R would repress Bcl-6 while keeping high levels of Blimp-1 and T-bet would direct them into the Th1- $\mathrm{T}_{\mathrm{EM}}$ phenotype (24, 110). Nevertheless, further research is needed to address how TCR signaling is connected to Bcl6, Blimp-1, or T-bet.

\section{MAINTAINING T CELL MEMORY}

CD4 and CD8 memory $\mathrm{T}$ cells exhibit distinct requirements for self-peptide-MHC signals to maintain their memory status. Different models have demonstrated that CD8 memory $\mathrm{T}$ cell longevity does not require tonic TCR signals $(111,112)$. On the contrary, self-p-MHC/TCR signals are pivotal for the survival of CD4 memory $\mathrm{T}$ cells although a comprehensive description of which type of TCR-dependent signaling cascades are supporting this process is still missing $(113,114)$. Assessing this would imply the use of conditional systems that allow for specific ablation of the particular signaling pathway at memory. In this line, two studies have addressed the role of early TCR signaling intermediates Lck and SLP-76 at memory using conditional deletion of the genes encoding these proteins. These studies surprisingly show that while Lck is not required for CD8 or CD4 T cell memory (54, $115,116)$, SLP-76 is crucial only for CD4 T cell memory homeostatic turnover (53). In studies exploring the role of mTORC1 and $\mathrm{NF \kappa B}$ signaling to maintain CD8 memory fate fidelity, we have found that $\mathrm{NF} \kappa \mathrm{B}$ signals are crucial to promote the longevity and the response of CD8 memory $\mathrm{T}$ cells. Interestingly, $\mathrm{NF \kappa B}$ at memory does not appear to be maintained by known extrinsic factors but rather is programed early in the response by TCR signals (Knudson and Teixeiro, manuscript in review), unfolding another unexpected role for TCR-dependent regulation in the maintenance of $\mathrm{T}$ cell memory.

\section{THE SYNERGY OF TCR AND INFLAMMATORY SIGNALS FOR T CELL MEMORY}

Cytokines in general have been proven to be crucial "transformers" of $\mathrm{T}$ cell differentiation covering from full acquisition of effector functions to the generation or maintenance of memory $\mathrm{T}$ cells $(117,118)$. Pro-inflammatory cytokines, in particular, have been suggested to control the sensitivity of the $\mathrm{T}$ cell response upon re-exposure to the same antigen (119). The converse axiom whether TCR signals regulate the input or sensitivity of inflammatory signals is also true. The strength of TCR signals can regulate the input of inflammation by directly controlling the expression of pro-inflammatory cytokine receptors and TGF $\beta R$ (23) on CD8 $\mathrm{T}$ cells. The same phenomenon has been reported for CD4 T cells (38) and together, strongly indicates that TCR signals govern sensitivity to inflammation and perhaps to other environmental signals (120) in a hierarchical multistage process.

Antigen and inflammation can, then, regulate each other's input at different points in the life of a T cell, but the thresholds of this regulation for each of the signals are unknown. Inflammation does not appear to compensate for weak $\mathrm{T}$ cell responses of TCR signal strengths that are well above the threshold for thymic selection (121). However, there may be other scenarios where these signals may cooperate or temper each other (122). This could happen at the most proximal membrane level or by regulating similar 
signaling pathways in the presence or in the absence of cognate antigen. Although this has not been fully explored, a few studies support this hypothesis. For example, it has been described that the chemokine receptor CXCR4, critical for $\mathrm{T}_{\mathrm{CM}}$ cell renewal and homing to the bone marrow $(123,124)$, physically associates with the TCR to signal in the absence of foreign antigen (125). This area of research certainly awaits further investigation and it can greatly aid in the identification of molecular checkpoints that can be exploited for therapeutics.

\section{CONCLUDING REMARKS}

Memory $\mathrm{T}$ cells are an essential part of our immune system that protect against pathogens and tumors. How memory $\mathrm{T}$ cells are generated and maintained are still unsolved questions. The memory $\mathrm{T}$ cell pool that remains upon infection or vaccination is heterogeneous, containing memory cells phenotypically diverse and with different specialized functions as well. This heterogeneity is the result of how the differentiating $\mathrm{T}$ cell integrates antigen, inflammation, costimulation, chemokine, homeostatic, and metabolic signals. At the beginning of the immune response, antigen receptor (TCR signals), pro-inflammatory cytokines (IL$12 \mathrm{R} /$ TypeIIFN), and costimulatory signals trigger the differentiation of $\mathrm{T}$ cells to acquire effector functions and to become memory cells. A fabulous effort in the field has provided ample insight into how inflammation impacts $\mathrm{T}$ cell memory differentiation and the diversity of the memory pool. However, recent data have brought up to stage the role of antigen and TCR

\section{REFERENCES}

1. Corse E, Gottschalk RA, Allison JP. Strength of TCR-peptide/MHC interactions and in vivo $\mathrm{T}$ cell responses. J Immunol (2011) 186:5039-45. doi:10.4049/ jimmunol.1003650

2. Kuhns MS, Davis MM. TCR signaling emerges from the sum of many parts. Front Immunol (2012) 3:159. doi:10.3389/fimmu.2012.00159

3. Masopust D, Kaech SM, Wherry EJ, Ahmed R. The role of programming in memory T-cell development. Curr Opin Immunol (2004) 16:217-25. doi:10. 1016/j.coi.2004.02.005

4. Busch DH, Pilip I, Pamer EG. Evolution of a complex T cell receptor repertoire during primary and recall bacterial infection. J Exp Med (1998) 188:61-70.

5. Crawford F, Kozono H, White J, Marrack P, Kappler J. Detection of antigenspecific T cells with multivalent soluble class II MHC covalent peptide complexes. Immunity (1998) 8:675-82.

6. Busch DH, Pamer EG. T cell affinity maturation by selective expansion during infection. J Exp Med (1999) 189:701-10.

7. Savage PA, Boniface JJ, Davis MM. A kinetic basis for T cell receptor repertoire selection during an immune response. Immunity (1999) 10:485-92.

8. Malherbe L, Hausl C, Teyton L, McHeyzer-Williams MG. Clonal selection of helper $\mathrm{T}$ cells is determined by an affinity threshold with no further skewing of TCR binding properties. Immunity (2004) 21:669-79. doi:10.1016/j.immuni. 2004.09.008

9. Kieper WC, Jameson SC. Homeostatic expansion and phenotypic conversion of naive T cells in response to self peptide/MHC ligands. Proc Natl Acad Sci U $S$ A (1999) 96:13306-11.

10. Zehn D, Lee SY, Bevan MJ. Complete but curtailed T-cell response to very low-affinity antigen. Nature (2009) 458:211-4. doi:10.1038/nature07657

11. Corse E, Gottschalk RA, Krogsgaard M, Allison JP. Attenuated T cell responses to a high-potency ligand in vivo. PLoS Biol (2010) 8:e1000481. doi:10.1371/ journal.pbio.1000481 signals in determining $\mathrm{T}$ cell memory. Experimental evidence supports that TCR signals are not a default but rather an essential component that enables the integration of all environmental cues that shape the $\mathrm{T}$ cell effector and memory pool. However, the mechanisms by which the TCR operates to control the final $\mathrm{T}$ cell's outcome are far from clear. As the different layers of regulation of TCR signaling unfold, more questions arise regarding how differences in TCR signal strength regulate the fidelity of the transcriptional program that controls memory development and memory quality or why specific TCR-dependent signaling pathways are more important than others at regulating $\mathrm{T}$ cell memory. Likewise, how TCR signaling cooperates in time and space with inflammatory and local tissue environmental signals and what their relative contribution is to memory differentiation is an exciting area that awaits further investigation and is expected to aid greatly in a better design of current immunotherapies.

\section{AUTHOR CONTRIBUTIONS}

MD wrote and edited the manuscript. ET wrote and edited the manuscript.

\section{ACKNOWLEDGMENTS}

Supported by the University of Missouri Mission Enhancement Fund and Ellis Fischel Leukemia Research Fund (MD) and by the US National Institute of Health (RO1 AI110420 to ET).

12. Sabatino JJ, Huang J, Zhu C, Evavold BD. High prevalence of low affinity peptide-MHC II tetramer-negative effectors during polyclonal CD4+ T cell responses. J Exp Med (2011) 208(1):81-90. doi:10.1084/jem.20101574

13. Sprent J, Surh CD. Normal T cell homeostasis: the conversion of naive cells into memory-phenotype cells. Nat Immunol (2011) 131:478-84. doi:10.1038/ ni. 2018

14. Govern CC, Paczosa MK, Chakraborty AK, Huseby ES. Fast on-rates allow short dwell time ligands to activate T cells. Proc Natl Acad Sci U S A (2010) 107:8724-9. doi:10.1073/pnas.1000966107

15. Tubo NJ, Pagan AJ, Taylor JJ, Nelson RW, Linehan JL, Ertelt JM, et al. Single naive CD4+ T cells from a diverse repertoire produce different effector cell types during infection. Cell (2013) 153:785-96. doi:10.1016/j.cell.2013.04.007

16. Kim C, Wilson T, Fischer KF, Williams MA. Sustained interactions between T cell receptors and antigens promote the differentiation of CD4(+) memory $\mathrm{T}$ cells. Immunity (2013) 39:508-20. doi:10.1016/j.immuni.2013.08.033

17. Daniels MA, Jameson SC. Critical role for CD8 in T cell receptor binding and activation by peptide/major histocompatibility complex multimers. J Exp Med (2000) 191:335-46. doi:10.1084/jem.191.2.335

18. van der Merwe PA, Davis SJ. Molecular interactions mediating T cell antigen recognition. Annu Rev Immunol (2003) 21:659-84. doi:10.1146/annurev. immunol.21.120601.141036

19. Henrickson SE, Perro M, Loughhead SM, Senman B, Stutte S, Quigley M, et al. Antigen availability determines CD8(+) T cell-dendritic cell interaction kinetics and memory fate decisions. Immunity (2013) 39:496-507. doi:10. 1016/j.immuni.2013.08.034

20. Badovinac VP, Messingham KAN, Jabbari A, Haring JS, Harty JT. Accelerated CD8+ T-cell memory and prime-boost response after dendritic-cell vaccination. Nat Med (2005) 11:748-56. doi:10.1038/nm1257

21. D'Souza WN, Hedrick SM. Cutting edge: latecomer CD8 T cells are imprinted with a unique differentiation program. J Immunol (2006) 177:777-81. doi:10. 4049/jimmunol.177.2.777 
22. Badovinac VP, Harty JT. Manipulating the rate of memory CD8+ T cell generation after acute infection. J Immunol (2007) 179:53-63. doi:10.4049/ jimmunol.179.1.53

23. Knudson KM, Goplen NP, Cunningham CA, Daniels MA, Teixeiro E. Lowaffinity $\mathrm{T}$ cells are programmed to maintain normal primary responses but are impaired in their recall to low-affinity ligands. Cell Rep (2013) 4:554-65. doi:10.1016/j.celrep.2013.07.008

24. Tubo NJ, Jenkins MK. TCR signal quantity and quality in CD4 T cell differentiation. Trends Immunol (2014) 35:591-6. doi:10.1016/j.it.2014.09.008

25. Kaech SM, Cui W. Transcriptional control of effector and memory CD8+ T cell differentiation. Nat Rev Immunol (2012) 12:749-61. doi:10.1038/nri3307

26. Restifo NP, Gattinoni L. Lineage relationship of effector and memory T cells. Curr Opin Immunol (2013) 25:556-63. doi:10.1016/j.coi.2013.09.003

27. Hogquist KA, Jameson SC. The self-obsession of T cells: how TCR signaling thresholds affect fate 'decisions' and effector function. Nat Immunol (2014) 15:815-23. doi:10.1038/ni.2938

28. Parello CS, Huseby ES. Indoctrinating T cells to attack pathogens through homeschooling. Trends Immunol (2015) 36:337-43. doi:10.1016/j.it.2015.04. 004

29. Valitutti S, Muller S, Dessing M, Lanzavecchia A. Different responses are elicited in cytotoxic $\mathrm{T}$ lymphocytes by different levels of $\mathrm{T}$ cell receptor occupancy. J Exp Med (1996) 183:1917-21.

30. Prlic M, Hernandez-Hoyos G, Bevan MJ. Duration of the initial TCR stimulus controls the magnitude but not functionality of the CD8+ T cell response. J Exp Med (2006) 203:2135-43. doi:10.1084/jem.20060928

31. Pham N-LL, Badovinac VP, Harty JT. A default pathway of memory CD8 T cell differentiation after dendritic cell immunization is deflected by encounter with inflammatory cytokines during antigen-driven proliferation. J Immunol (2009) 183:2337-48. doi:10.4049/jimmunol.0901203

32. Roychoudhuri R, Lefebvre F, Honda M, Pan L, Ji Y, Klebanoff CA, et al. Transcriptional profiles reveal a stepwise developmental program of memory CD8(+) T cell differentiation. Vaccine (2015) 33:914-23. doi:10.1016/j. vaccine.2014.10.007

33. Kedzierska K, Venturi V, Field K, Davenport M, Turner SJ, Doherty PC. Early establishment of diverse $\mathrm{T}$ cell receptor profiles for influenza-specific CD8(+)CD62L(hi) memory T cells. Proc Natl Acad Sci U S A (2006) 103:9184-9. doi:10.1073/pnas.0603289103

34. Turner SJ, La Gruta NL, Kedzierska K, Thomas PG, Doherty PC. Functional implications of T cell receptor diversity. Curr Opin Immunol (2009) 21:286-90. doi:10.1016/j.coi.2009.05.004

35. Stemberger C, Huster KM, Koffler M, Anderl F, Schiemann M, Wagner H, et al. A single naive CD8+ T cell precursor can develop into diverse effector and memory subsets. Immunity (2007) 27:985-97. doi:10.1016/j.immuni. 2007.10.012

36. Gerlach C, Rohr JC, Perie L, van Rooij N, van Heijst JW, Velds A, et al. Heterogeneous differentiation patterns of individual CD8+ T cells. Science (2013) 340(6132):635-9. doi:10.1126/science.1235487

37. Plumlee CR, Sheridan BS, Cicek BB, Lefrançois L. Environmental cues dictate the fate of individual CD8+ T cells responding to infection. Immunity (2013) 39:347-56. doi:10.1016/j.immuni.2013.07.014

38. van Panhuys N, Klauschen F, Germain RN. T-cell-receptor-dependent signal intensity dominantly controls CD4(+) T cell polarization in vivo. Immunity (2014) 41:63-74. doi:10.1016/j.immuni.2014.06.003

39. Teixeiro E, Daniels M, Hamilton S, Schrum A, Bragado R, Jameson S, et al. Different $\mathrm{T}$ cell receptor signals determine CD8+ memory versus effector development. Science (2009) 323:502. doi:10.1126/science.1163612

40. Gattinoni L, Zhong X-S, Palmer DC, Ji Y, Hinrichs CS, Yu Z, et al. Wnt signaling arrests effector $\mathrm{T}$ cell differentiation and generates CD8+ memory stem cells. Nat Med (2009) 15:808-13. doi:10.1038/nm.1982

41. Rao RR, Li Q, Odunsi K, Shrikant PA. The mTOR Kinase determines effector versus memory CD8+ T cell fate by regulating the expression of transcription factors T-bet and eomesodermin. Immunity (2010) 32(1):67-78. doi:10.1016/ j.immuni.2009.10.010

42. Knudson KM, Hamilton SE, Daniels MA, Jameson SC, Teixeiro E. Cutting edge: the signals for the generation of $\mathrm{T}$ cell memory are qualitatively different depending on TCR ligand strength. J Immunol (2013) 191:5797-801. doi:10. 4049/jimmunol.1300905

43. Szabo SJ, Kim ST, Costa GL, Zhang X, Fathman CG, Glimcher LH. A novel transcription factor, T-bet, directs Th1 lineage commitment. Cell (2000) 100:655-69. doi:10.1016/S0092-8674(00)80702-3
44. Johnston RJ, Poholek AC, DiToro D, Yusuf I, Eto D, Barnett B, et al. Bcl6 and Blimp-1 are reciprocal and antagonistic regulators of $\mathrm{T}$ follicular helper cell differentiation. Science (2009) 325:1006-10. doi:10.1126/science.1175870

45. Kallies A, Hawkins ED, Belz GT, Metcalf D, Hommel M, Corcoran LM, et al. Transcriptional repressor Blimp-1 is essential for T cell homeostasis and selftolerance. Nat Immunol (2006) 7:466-74. doi:10.1038/ni1321

46. Schulz EG, Mariani L, Radbruch A, Höfer T. Sequential polarization and imprinting of type $1 \mathrm{~T}$ helper lymphocytes by interferon-gamma and interleukin-12. Immunity (2009) 30:673-83. doi:10.1016/j.immuni.2009. 03.013

47. Azzam HS, Grinberg A, Lui K, Shen H, Shores EW, Love PE. CD5 expression is developmentally regulated by T cell receptor (TCR) signals and TCR avidity. JExp Med (1998) 188:2301-11.

48. Perez-Villar JJ, Whitney GS, Bowen MA, Hewgill DH, Aruffo AA, Kanner SB. CD5 negatively regulates the T-cell antigen receptor signal transduction pathway: involvement of SH2-containing phosphotyrosine phosphatase SHP1. Mol Cell Biol (1999) 19:2903-12.

49. Weber KS, Li QJ, Persaud SP, Campbell JD, Davis MM, Allen PM. Distinct CD4+ helper T cells involved in primary and secondary responses to infection. Proc Natl Acad Sci U S A (2012) 109:9511-6. doi:10.1073/pnas.1202408109

50. Persaud SP, Parker CR, Lo WL, Weber KS, Allen PM. Intrinsic CD4+ T cell sensitivity and response to a pathogen are set and sustained by avidity for thymic and peripheral complexes of self peptide and MHC. Nat Immunol (2014) 15:266-74. doi:10.1038/ni.2822

51. Fulton RB, Hamilton SE, Xing Y, Best JA, Goldrath AW, Hogquist KA, et al. The TCR's sensitivity to self peptide-MHC dictates the ability of naive CD8(+) T cells to respond to foreign antigens. Nat Immunol (2015) 16:107-17. doi:10. 1038/ni.3043

52. Smith-Garvin JE, Burns JC, Gohil M, Zou T, Kim JS, Maltzman JS, et al. T-cell receptor signals direct the composition and function of the memory CD8+ T-cell pool. Blood (2010) 116:5548-59. doi:10.1182/blood-2010-06-292748

53. Bushar ND, Corbo E, Schmidt M, Maltzman JS, Farber DL. Ablation of SLP76 signaling after $\mathrm{T}$ cell priming generates memory CD4 $\mathrm{T}$ cells impaired in steady-state and cytokine-driven homeostasis. Proc Natl Acad Sci U S A (2010) 107:827-31. doi:10.1073/pnas.0908126107

54. Wiehagen K, Corbo E, Schmidt M, Shin H, Wherry E, Maltzman J. Loss of tonic T-cell receptor signals alters the generation but not the persistence of CD8+ memory T cells. Blood (2010) 116:5560. doi:10.1182/blood-2010-06-292458

55. Pearce E, Walsh M, Cejas P, Harms G, Shen H, Wang L, et al. Enhancing CD8 T-cell memory by modulating fatty acid metabolism. Nature (2009) 460(7251):103-7. doi:10.1038/nature08097

56. Cui W, Liu Y, Weinstein JS, Craft J, Kaech SM. An interleukin-21 - interleukin10-STAT3 pathway is critical for functional maturation of memory CD8+ T cells. Immunity (2011) 35:792-805. doi:10.1016/j.immuni.2011.09.017

57. Smith-Garvin J, Koretzky G, Jordan M. T cell activation. Annu Rev Immunol (2009) 27:591-619. doi:10.1146/annurev.immunol.021908.132706

58. Cunningham CA, Knudson KM, Peng BJ, Teixeiro E, Daniels MA. The POSH/JIP-1 scaffold network regulates TCR-mediated JNK1 signals and effector function in CD8(+) T cells. Eur J Immunol (2013) 43(12):3361-71. doi:10. 1002/eji.201343635

59. Parry RV, Reif K, Smith G, Sansom DM, Hemmings BA, Ward SG. Ligation of the $\mathrm{T}$ cell co-stimulatory receptor $\mathrm{CD} 28$ activates the serine-threonine protein kinase protein kinase B. Eur J Immunol (1997) 27:2495-501. doi:10.1002/eji. 1830271006

60. Kong K-F, Yokosuka T, Canonigo-Balancio AJ, Isakov N, Saito T, Altman A. A motif in the $\mathrm{V} 3$ domain of the kinase PKC- $\theta$ determines its localization in the immunological synapse and functions in T cells via association with CD28. Nat Immunol (2011) 12:1105-12. doi:10.1038/ni.2120

61. So T, Soroosh P, Eun SY, Altman A, Croft M. Antigen-independent signalosome of CARMA1, PKCtheta, and TNF receptor-associated factor 2 (TRAF2) determines NF-kappaB signaling in T cells. Proc Natl Acad Sci U S A (2011) 108:2903-8. doi:10.1073/pnas.1008765108

62. Gerondakis S, Fulford TS, Messina NL, Grumont RJ. NF-kappaB control of T cell development. Nat Immunol (2014) 15:15-25. doi:10.1038/ni.2785

63. Courtois G, Smahi A, Reichenbach J, Döffinger R, Cancrini C, Bonnet M, et al. A hypermorphic $\mathrm{I} \kappa \mathrm{B} \alpha$ mutation is associated with autosomal dominant anhidrotic ectodermal dysplasia and $\mathrm{T}$ cell immunodeficiency. J Clin Invest (2003) 112:1108-15. doi:10.1172/JCI18714

64. Hettmann T, Opferman JT, Leiden JM, Ashton-Rickardt PG. A critical role for NF-kappaB transcription factors in the development of CD8+ 
memory-phenotype T cells. Immunol Lett (2003) 85:297-300. doi:10.1016/ S0165-2478(02)00260-2

65. Schmidt-Supprian M, Courtois G, Tian J, Coyle AJ, Israël A, Rajewsky K, et al. Mature T cells depend on signaling through the IKK complex. Immunity (2003) 19:377-89. doi:10.1016/S1074-7613(03)00237-1

66. Sriskantharajah S, Belich MP, Papoutsopoulou S, Janzen J, Tybulewicz V, Seddon B, et al. Proteolysis of NF- $\kappa$ B1 p105 is essential for T cell antigen receptor-induced proliferation. Nat Immunol (2008) 10:38-47. doi:10.1038/ni. 1685

67. Rowe AM, Murray SE, Raue HP, Koguchi Y, Slifka MK, Parker DC. A cellintrinsic requirement for NF-kappaB-inducing kinase in CD4 and CD8 T cell memory. J Immunol (2013) 191:3663-72. doi:10.4049/jimmunol.1301328

68. Krishna S, Xie D, Gorentla B, Shin J, Gao J, Zhong X-P. Chronic activation of the kinase IKK $\beta$ impairs T cell function and survival. J Immunol (2012) 189:1209-19. doi:10.4049/jimmunol.1102429

69. Paul S, Schaefer BC. A new look at T cell receptor signaling to nuclear factor$\kappa B$. Trends Immunol (2013) 34(6):269-81. doi:10.1016/j.it.2013.02.002

70. Schmidt C, Peng B, Li Z, Sclabas GM, Fujioka S, Niu J, et al. Mechanisms of proinflammatory cytokine-induced biphasic NF-kappaB activation. Mol Cell (2003) 12:1287-300. doi:10.1016/S1097-2765(03)00390-3

71. Nelson DE, Ihekwaba AEC, Elliott M, Johnson JR, Gibney CA, Foreman $\mathrm{BE}$, et al. Oscillations in NF-kappaB signaling control the dynamics of gene expression. Science (2004) 306:704-8. doi:10.1126/science.1099962

72. Shih VF-S, Kearns JD, Basak S, Savinova OV, Ghosh G, Hoffmann A. Kinetic control of negative feedback regulators of NF-kappaB/RelA determines their pathogen- and cytokine-receptor signaling specificity. Proc Natl Acad Sci U S A (2009) 106:9619-24. doi:10.1073/pnas.0812367106

73. Tay S, Hughey JJ, Lee TK, Lipniacki T, Quake SR, Covert MW. Singlecell NF-kappaB dynamics reveal digital activation and analogue information processing. Nature (2010) 466:267-71. doi:10.1038/nature09145

74. Jimi E, Strickland I, Voll RE, Long M, Ghosh S. Differential role of the transcription factor NF-kappaB in selection and survival of CD4+ and CD8+ thymocytes. Immunity (2008) 29:523-37. doi:10.1016/j.immuni.2008.08.010

75. Liu HH, Xie M, Schneider MD, Chen ZJ. Essential role of TAK1 in thymocyte development and activation. Proc Natl Acad Sci U S A (2006) 103:11677-82. doi:10.1073/pnas.0603089103

76. Marsland BJ. Protein kinase $\mathrm{C}$ is critical for the development of in vivo $\mathrm{T}$ helper (Th)2 cell but not Th1 cell responses. J Exp Med (2004) 200:181-9. doi:10.1084/jem.20032229

77. Sakaguchi S, Yamaguchi T, Nomura T, Ono M. Regulatory T cells and immune tolerance. Cell (2008) 133:775-87. doi:10.1016/j.cell.2008.05.009

78. Molinero LL, Yang J, Gajewski T, Abraham C, Farrar MA, Alegre ML. CARMA1 controls an early checkpoint in the thymic development of FoxP3+ regulatory T cells. J Immunol (2009) 182:6736-43. doi:10.4049/jimmunol. 0900498

79. Medoff BD, Sandall BP, Landry A, Nagahama K, Mizoguchi A, Luster AD, et al. Differential requirement for CARMA1 in agonist-selected T-cell development. Eur J Immunol (2009) 39:78-84. doi:10.1002/eji.200838734

80. Torres JM, Martinez-Barricarte R, Garcia-Gomez S, Mazariegos MS, Itan Y, Boisson B, et al. Inherited BCL10 deficiency impairs hematopoietic and nonhematopoietic immunity. J Clin Invest (2014) 124:5239-48. doi:10.1172/ JCI77493

81. King CG, Kobayashi T, Cejas PJ, Kim T, Yoon K, Kim GK, et al. TRAF6 is a $\mathrm{T}$ cell-intrinsic negative regulator required for the maintenance of immune homeostasis. Nat Med (2006) 12:1088-92. doi:10.1038/nm1449

82. Iborra S, Soto M, Stark-Aroeira L, Castellano E, Alarcón B, Alonso C, et al. Hras and $\mathrm{N}$-ras are dispensable for T-cell development and activation but critical for protective Th1 immunity. Blood (2011) 117:5102-11. doi:10.1182/blood2010-10-315770

83. Iborra S, Ramos M, Arana DM, Lazaro S, Aguilar F, Santos E, et al. N-ras couples antigen receptor signaling to eomesodermin and to functional CD8+ T cell memory but not to effector differentiation. J Exp Med (2013) 210:1463-79. doi:10.1084/jem.20112495

84. Li Q, Rao RR, Araki K, Pollizzi K, Odunsi K, Powell JD, et al. A central role for mTOR kinase in homeostatic proliferation induced CD8+ T cell memory and tumor immunity. Immunity (2011) 34:541-53. doi:10.1016/j.immuni. 2011.04.006

85. Exley M, Varticovski L, Peter M, Sancho J, Terhorst C. Association of phosphatidylinositol 3-kinase with a specific sequence of the $\mathrm{T}$ cell receptor zeta chain is dependent on T cell activation. J Biol Chem (1994) 269 15140-6.

86. Hamilton KS, Phong B, Corey C, Cheng J, Gorentla B, Zhong X, et al. T cell receptor-dependent activation of mTOR signaling in $\mathrm{T}$ cells is mediated by Carmal and MALT1, but not Bcl10. Sci Signal (2014) 7:ra55. doi:10.1126/ scisignal.2005169

87. Laplante M, Sabatini DM. mTOR signaling at a glance. J Cell Sci (2009) 122:3589-94. doi:10.1242/jcs.051011

88. Sarbassov DD, Guertin DA, Ali SM, Sabatini DM. Phosphorylation and regulation of Akt/PKB by the rictor-mTOR complex. Science (2005) 307:1098-101. doi:10.1126/science.1106148

89. Pollizzi KN, Patel CH, Sun IH, Oh MH, Waickman AT, Wen J, et al. mTORC1 and mTORC2 selectively regulate CD8(+) T cell differentiation. J Clin Invest (2015) 125:2090-108. doi:10.1172/JCI77746

90. Nayar R, Enos M, Prince A, Shin H, Hemmers S, Jiang JK, et al. TCR signaling via Tec kinase ITK and interferon regulatory factor 4 (IRF4) regulates CD8+ T-cell differentiation. Proc Natl Acad Sci U S A (2012) 109:E2794-802. doi:10. 1073/pnas. 1205742109

91. Man K, Kallies A. Synchronizing transcriptional control of T cell metabolism and function. Nat Rev Immunol (2015) 15:574-84. doi:10.1038/nri3874

92. Finlay D, Cantrell D. Phosphoinositide 3-kinase and the mammalian target of rapamycin pathways control T cell migration. Ann N Y Acad Sci (2010) 1183:149-57. doi:10.1111/j.1749-6632.2009.05134.x

93. Skon CN, Lee JY, Anderson KG, Masopust D, Hogquist KA, Jameson SC. Transcriptional downregulation of S1prl is required for the establishment of resident memory CD8+ T cells. Nat Immunol (2013) 14:1285-93. doi:10.1038/ ni. 2745

94. Boudousquie C, Danilo M, Pousse L, Jeevan-Raj B, Angelov GS, Chennupati $\mathrm{V}$, et al. Differences in the transduction of canonical Wnt signals demarcate effector and memory CD8 T cells with distinct recall proliferation capacity. $J$ Immunol (2014) 193:2784-91. doi:10.4049/jimmunol.1400465

95. Prlic M, Bevan MJ. Cutting edge: $\beta$-catenin is dispensable for $\mathrm{T}$ cell effector differentiation, memory formation, and recall responses. J Immunol (2011) 187:1542-6. doi:10.4049/jimmunol.1100907

96. Zhou X, Yu S, Zhao D-M, Harty JT, Badovinac VP, Xue H-H. Differentiation and persistence of memory CD8(+) T cells depend on T cell factor 1. Immunity (2010) 33:229-40. doi:10.1016/j.immuni.2010.08.002

97. Lovatt M, Bijlmakers M-J. Stabilisation of $\beta$-catenin downstream of $\mathrm{T}$ cell receptor signalling. PLoS One (2010) 5:e12794. doi:10.1371/journal.pone. 0012794

98. Kim EH, Sullivan JA, Plisch EH, Tejera MM, Jatzek A, Choi KY, et al. Signal integration by akt regulates CD8 T cell effector and memory differentiation. $J$ Immunol (2012) 188:4305-14. doi:10.4049/jimmunol.1103568

99. Inoki K, Ouyang H, Zhu T, Lindvall C, Wang Y, Zhang X, et al. TSC2 integrates Wnt and energy signals via a coordinated phosphorylation by AMPK and GSK3 to regulate cell growth. Cell (2006) 126:955-68. doi:10.1016/j.cell.2006. 06.055

100. Lee DF, Kuo HP, Chen CT, Hsu JM, Chou CK, Wei Y, et al. IKK beta suppression of TSC1 links inflammation and tumor angiogenesis via the mTOR pathway. Cell (2007) 130:440-55. doi:10.1016/j.cell.2007.05.058

101. Minhajuddin M, Fazal F, Bijli KM, Amin MR, Rahman A. Inhibition of mammalian target of rapamycin potentiates thrombin-induced intercellular adhesion molecule-1 expression by accelerating and stabilizing NF-kappa B activation in endothelial cells. J Immunol (2005) 174:5823-9. doi:10.4049/ jimmunol.174.9.5823

102. Sowell RT, Rogozinska M, Nelson CE, Vezys V, Marzo AL. Cutting edge: generation of effector cells that localize to mucosal tissues and form resident memory CD8 T cells is controlled by mTOR. J Immunol (2014) 193:2067-71. doi:10.4049/jimmunol.1400074

103. Casey KA, Fraser KA, Schenkel JM, Moran A, Abt MC, Beura LK, et al. Antigen-independent differentiation and maintenance of effector-like resident memory $\mathrm{T}$ cells in tissues. J Immunol (2012) 188:4866-75. doi:10.4049/ jimmunol.1200402

104. Mackay LK, Stock AT, Ma JZ, Jones CM, Kent SJ, Mueller SN, et al. Longlived epithelial immunity by tissue-resident memory T (TRM) cells in the absence of persisting local antigen presentation. Proc Natl Acad Sci U S A (2012) 109:7037-42. doi:10.1073/pnas.1202288109

105. Schenkel JM, Masopust D. Tissue-resident memory T cells. Immunity (2014) 41:886-97. doi:10.1016/j.immuni.2014.12.007 
106. Carbone FR. Tissue-resident memory $\mathrm{T}$ cells and fixed immune surveillance in nonlymphoid organs. J Immunol (2015) 195:17-22. doi:10.4049/jimmunol. 1500515

107. Pepper M, Jenkins MK. Origins of CD4+ effector and central memory T cells. Nat Immunol (2011) 131:467-71. doi:10.1038/ni.2038

108. Pepper M, Pagán AJ, Igyártó BZ, Taylor JJ, Jenkins MK. Opposing signals from the bcl6 transcription factor and the interleukin-2 receptor generate $\mathrm{T}$ helper 1 central and effector memory cells. Immunity (2011) 35:583-95. doi:10.1016/j.immuni.2011.09.009

109. Cimmino L, Martins GA, Liao J, Magnusdottir E, Grunig G, Perez RK, et al. Blimp-1 attenuates Th1 differentiation by repression of ifng, tbx 21 , and bcl6 gene expression. J Immunol (2008) 181:2338-47. doi:10.4049/jimmunol.181. 4.2338

110. Oestreich KJ, Mohn SE, Weinmann AS. Molecular mechanisms that control the expression and activity of Bcl- 6 in $\mathrm{T}(\mathrm{H}) 1$ cells to regulate flexibility with a T(FH)-like gene profile. Nat Immunol (2012) 13(4):405-11. doi:10.1038/ni. 2242

111. Murali-Krishna K, Lau LL, Sambhara S, Lemonnier F, Altman J, Ahmed R. Persistence of memory CD8 T cells in MHC class I-deficient mice. Science (1999) 286:1377-81.

112. Leignadier J, Rooney J, Daudelin J-F, Labrecque N. Lowering TCR expression on naive CD8(+) T cells does not affect memory T-cell differentiation. Immunol Cell Biol (2010) 89(2):322-5. doi:10.1038/icb.2010.80

113. Kassiotis G, Garcia S, Simpson E, Stockinger B. Impairment of immunological memory in the absence of MHC despite survival of memory T cells. Nat Immunol (2002) 3:244-50. doi:10.1038/ni766

114. De Riva A, Bourgeois C, Kassiotis G, Stockinger B. Noncognate interaction with MHC class II molecules is essential for maintenance of $\mathrm{T}$ cell metabolism to establish optimal memory CD4 T cell function. J Immunol (2007) 178:5488-95. doi:10.4049/jimmunol.178.9.5488

115. Seddon B, Seddon B, Tomlinson P, Tomlinson P, Zamoyska R, Zamoyska R. Interleukin 7 and $\mathrm{T}$ cell receptor signals regulate homeostasis of CD4 memory cells. Nat Immunol (2003) 4:680. doi:10.1038/ni946

116. Tewari K, Walent J, Svaren J, Zamoyska R, Suresh M. Differential requirement for Lck during primary and memory CD8+ T cell responses. Proc Natl Acad Sci U S A (2006) 103:16388-93. doi:10.1073/pnas.0602565103

117. Mescher MF, Curtsinger JM, Agarwal P, Casey KA, Gerner M, Hammerbeck $\mathrm{CD}$, et al. Signals required for programming effector and memory development by CD8+ T cells. Immunol Rev (2006) 211:81-92. doi:10.1111/ j.0105-2896.2006.00382.x
118. Xiao Z, Casey KA, Jameson SC, Curtsinger JM, Mescher MF. Programming for CD8 T cell memory development requires IL-12 or type I IFN. J Immunol (2009) 182:2786-94. doi:10.4049/jimmunol.0803484

119. Richer MJ, Nolz JC, Harty JT. Pathogen-specific inflammatory milieux tune the antigen sensitivity of CD8(+) T cells by enhancing T cell receptor signaling. Immunity (2013) 38:140-52. doi:10.1016/j.immuni.2012.09.017

120. Ballesteros-Tato A, Leon B, Lee BO, Lund FE, Randall TD. Epitope-specific regulation of memory programming by differential duration of antigen presentation to influenza-specific CD8(+) T cells. Immunity (2014) 41:127-40. doi:10.1016/j.immuni.2014.06.007

121. Zehn D, Roepke S, Weakly K, Bevan MJ, Prlic M. Inflammation and TCR signal strength determine the breadth of the $\mathrm{T}$ cell response in a bim-dependent manner. J Immunol (2014) 192:200-5. doi:10.4049/jimmunol. 1302289

122. Huang W, August A. The signaling symphony: T cell receptor tunes cytokinemediated T cell differentiation. J Leukoc Biol (2015) 97:477-85. doi:10.1189/ jlb.1RI0614-293R

123. Banerjee A, Gordon SM, Intlekofer AM, Paley MA, Mooney EC, Lindsten T, et al. Cutting edge: the transcription factor eomesodermin enables CD8+ T cells to compete for the memory cell niche. J Immunol (2010) 185:4988-92. doi:10.4049/jimmunol.1002042

124. Chaix J, Nish SA, Lin WH, Rothman NJ, Ding L, Wherry EJ, et al. Cutting edge: CXCR4 is critical for CD8+ memory $\mathrm{T}$ cell homeostatic self-renewal but not rechallenge self-renewal. J Immunol (2014) 193:1013-6. doi:10.4049/ jimmunol.1400488

125. Kumar A, Humphreys TD, Kremer KN, Bramati PS, Bradfield L, Edgar CE, et al. CXCR4 physically associates with the $\mathrm{T}$ cell receptor to signal in T cells. Immunity (2006) 25:213-24. doi:10.1016/j.immuni.2006.06.015

Conflict of Interest Statement: The authors declare that the research was conducted in the absence of any commercial or financial relationships that could be construed as a potential conflict of interest.

Copyright (c) 2015 Daniels and Teixeiro. This is an open-access article distributed under the terms of the Creative Commons Attribution License (CC BY). The use, distribution or reproduction in other forums is permitted, provided the original author $(s)$ or licensor are credited and that the original publication in this journal is cited, in accordance with accepted academic practice. No use, distribution or reproduction is permitted which does not comply with these terms. 